\title{
Post-Traumatic Growth among High School Students during the COVID-19 Pandemic: A Survey Study
}

\author{
Elis A. Kristo \\ Newton North High School, Newton, MA, USA \\ Email: eliskristo@gmail.com
}

How to cite this paper: Kristo, E. A. (2021). Post-Traumatic Growth among High School Students during the COVID-19 Pandemic: A Survey Study. Creative Education, 12, 1600-1607.

https://doi.org/10.4236/ce.2021.127121

Received: June 2, 2021

Accepted: July 11, 2021

Published: July 14, 2021

Copyright ( 2021 by author(s) and Scientific Research Publishing Inc. This work is licensed under the Creative Commons Attribution International License (CC BY 4.0).

http://creativecommons.org/licenses/by/4.0/

\section{(c) (i) Open Access}

\begin{abstract}
Background: Following major life crisis or traumatic events, people can change their perspectives and experience personal growth, a process known as posttraumatic growth (PTG). The goal of this study was to evaluate the stress experienced by high school students during the COVID-19 pandemic and to determine whether they have experienced post-traumatic growth. Methods: An anonymous online survey regarding stress and PTG related to the COVID-19 pandemic was distributed to 500 students from a high school in Massachusetts between March 01-21, 2021. Results: A total of 167 of 500 surveys were completed (33.4\% response rate). Most students (83.2\%) reported moderate and severe stress during the COVID-19 pandemic, with more 12th grade students experienced severe stress (40.0\% vs. $34.0 \%$ of 11 graders, $34.3 \%$ of 10 graders, and $22.5 \%$ of 9 th graders). Furthermore, more female students experienced severe stress ( $40.7 \%$ vs. $22.5 \%$ of males). Participants were most stressed about the outlook for their future, followed by social isolation, personal or familial risk of becoming infected with COVID-19, the quality of education during the pandemic, and financial difficulties. The most positive COVID-19 related change reported by the surveyed students was increased compassion for others, followed by development of new interests, feeling that they can rely on people in times of trouble, increased willingness to try to change situations that they are unsatisfied with, changed priorities about what is important in life, greater appreciation for their own life's value, better able to accept the way things work out, greater sense of personal strength, increased appreciation of each day, greater sense of closeness with others, being more willing to express emotions, appreciation of new opportunities, and better understanding of spiritual matters. Female participants reported more personal growth in all PTG categories. Conclusions: While high school students experience significant stress during the COVID-19 pandemic, this study suggests that they can also experience positive life changes
\end{abstract}


as a result of such a traumatic event. Teachers, counselors, and parents should work together to adequately support high school students during the COVID-19 pandemic.

\section{Keywords}

COVID-19 Pandemic, High School Students, Stress, Posttraumatic Growth

\section{Introduction}

The life-threatening risk of the COVID-19 pandemic has caused considerable mental health problems, including insecurity, anxiety, depression, and posttraumatic stress disorder in healthcare workers (Cabarkapa, Nadjidai, Murgier, \& Ng, 2020; Shanafelt, Ripp, \& Trockel, 2020) as well as in the general population (CDC, n.d.; Salari, Hosseinian-Far, Jalali et al., 2020).

Although people respond to adversity and stress in various ways, there is evidence that people can change their perspectives and experience personal growth as a result of major life crisis or traumatic events. This process is known as post-traumatic growth (PTG) and was first described by Tedeschi and Calhoun in 1996 (Tedeschi \& Calhoun, 1996). PTG is characterized by positive adjustments that occur following severe traumatic experiences and includes five major aspects: forging stronger relationships with others, increased perception of personal strength, willingness to embrace new possibilities, deeper appreciation of life, and increased spirituality (Tedeschi \& Calhoun, 1996; Tedeschi \& Calhoun, 2004).

Several studies have shown the COVID-19 pandemic has been associated with PTG in students that have graduated high school (Yu, Yu, \& Hu, 2021) and in college students (Kutza \& Cornell., 2021; Zeng, Zeng, Xu et al., 2021). However, it remains unknown whether PTG occurs in current high school students as a result of the stress experienced during the coronavirus pandemic.

As such, the goal of this study was to evaluate the stress experienced by high school students during the COVID-19 pandemic and to determine whether they have experienced post-traumatic growth.

\section{Methods}

An anonymous survey regarding stress related to the COVID-10 pandemic was distributed using an internet-based survey tool (SurveyMonkey ${ }^{\circledR}$ ) to $500 \mathrm{stu}$ dents from a high school in Massachusetts between March 01-21, 2021.

The survey consisted of 6 questions structured as multiple-choice items or as statements with a 5-point Likert response scale (Supplement). Each participant was able to respond only once to the survey. Completion of the survey was voluntary, and anonymity was ensured by not requiring any personal identifiers. Participants were informed in writing that by answering the questions and returning the survey, they were providing and documenting their willingness to 
participate. Results were calculated based on the number of responses received to each individual question.

\section{Results}

A total of 167 of 500 surveys were completed (33.4\% response rate). The demographic characteristics of our survey participants are displayed in Table 1.

When asked about the level of personal stress experienced during the COVID-19 pandemic, most students (83.2\%) reported moderate and severe stress (Figure $1)$. When stratified by grade level, more $12^{\text {th }}$ grade students experienced severe stress $\left(40.0 \%\right.$ vs. $34.0 \%$ of 11 graders, $34.3 \%$ of 10 graders, and $22.5 \%$ of $9^{\text {th }}$

Table 1. Demographic characteristics of survey respondents.

\begin{tabular}{|c|c|c|}
\hline & eristics & $\mathrm{N}(\%)$ \\
\hline \multirow{4}{*}{ Current grade } & 9-th grade & $40(24.0 \%)$ \\
\hline & 10-th grade & $35(21.0 \%)$ \\
\hline & 11-th grade & $47(28.1 \%)$ \\
\hline & 12-th grade & $45(26.9 \%)$ \\
\hline \multirow{3}{*}{ Gender } & Female & $91(54.5 \%)$ \\
\hline & Male & $71(42.5 \%)$ \\
\hline & Not specified & $5(3.0 \%)$ \\
\hline \multirow{6}{*}{ Ethnicity } & White & $113(67.7 \%)$ \\
\hline & Asian or Pacific Islander & $18(10.8 \%)$ \\
\hline & Hispanic & $15(9.0 \%)$ \\
\hline & African American & $8(4.8 \%)$ \\
\hline & Multiracial & $11(6.6 \%)$ \\
\hline & Not specified & $2(1.2 \%)$ \\
\hline
\end{tabular}

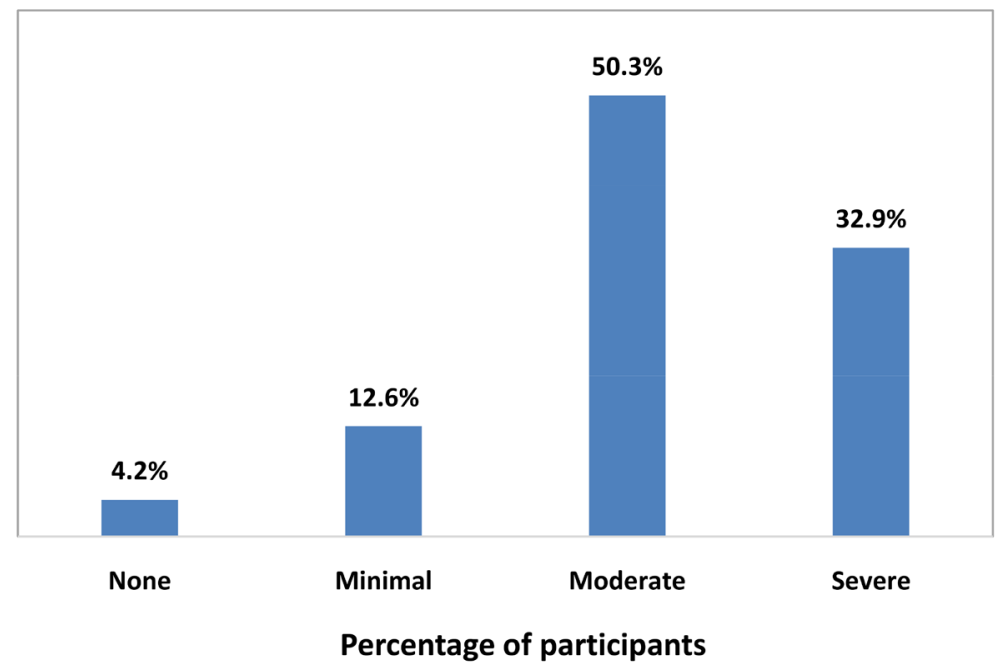

Figure 1. Level of stress experienced during the COVID-19 pandemic. 
graders). Furthermore, more female students experienced severe stress (40.7\% vs. $22.5 \%$ of males).

Participants were most stressed about the outlook for their future $(4.14 / 5$ on a Likert scale), followed by social isolation (3.86/5), personal or familial risk of becoming infected with COVID-19 (3.80/5), the quality of education during the pandemic (3.45/5), and financial difficulties (2.53/5) (Figure 2).

Other reported stressors included worries about their mental health (10 respondents), college application and transition to college (7), reduced sport and physical activities (6), racial minorities being affected more by the COVID-19 pandemic (3), potential cancellation of graduation events (1), and lack of sense of school community (1).

The most positive COVID-19 related change reported by the surveyed high school students was increased compassion for others, followed by development of new interests, feeling that they can rely on people in times of trouble, increased willingness to try to change situations that they are unsatisfied with, changed priorities about what is important in life, greater appreciation for their own life's value, better able to accept the way things work out, greater sense of personal strength, increased appreciation of each day, greater sense of closeness with others, being more willing to express emotions, appreciation of new opportunities, and better understanding of spiritual matters (Table 2). Female participants reported more personal growth in all PTG categories.

There were no other differences in participant responses when stratified by gender, ethnicity, and grade level.

\section{Discussion}

The results of our study show that high school students experience significant levels of stress related to the COVID-19 pandemic. Interestingly, female students as well as $12^{\text {th }}$ graders reported significantly higher level of severe stress.

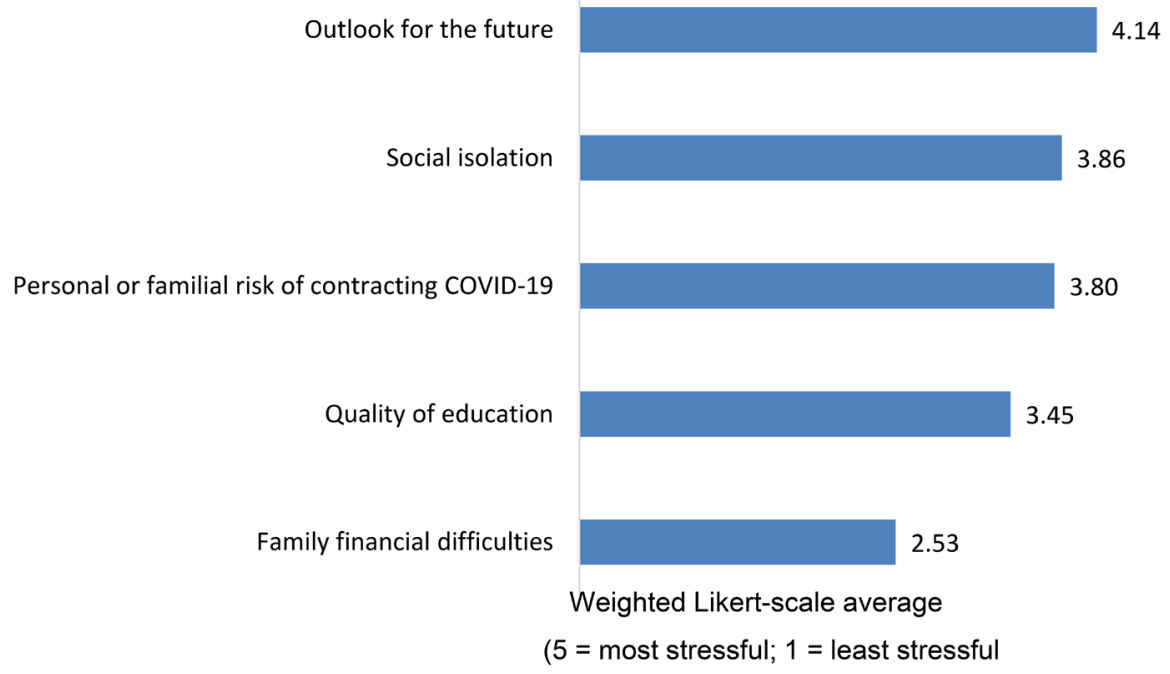

Figure 2. Stressful issues during the COVID-19 pandemic. 
Table 2. New perspectives developed as a result of the COVID-19 pandemic.

\begin{tabular}{cc}
\hline Perspective & $\begin{array}{c}\text { Average Likert-scale } \\
\text { response } \\
\text { [ } \begin{array}{c}\text { strongly agree; } 1= \\
\text { strongly disagree }]\end{array}\end{array}$ \\
I have more compassion for others & 3.95 \\
I developed new interests & 3.89 \\
I feel I can rely on people in times of trouble & 3.65 \\
I am more likely to try to change things that I am unsatisfied with & 3.59 \\
I changed my priorities about what is important in life & 3.55 \\
I have a greater appreciation for my own life's value & 3.55 \\
I am better able to accept the way things work out & 3.54 \\
I discovered that I'm stronger than I thought I was & 3.42 \\
I appreciate each day more & 3.26 \\
I have a greater sense of closeness with others & 3.26 \\
I am more willing to express my emotions & 3.16 \\
New opportunities are available which wouldn't have been otherwise & 3.13 \\
I have a better understanding of spiritual matters & 2.57 \\
\hline
\end{tabular}

The self-reported gender differences related to stress shown in this study are well-acknowledged in the literature. According to the American Psychological Association, females are more likely to report stress and symptoms associated with stress, and manage the stress in different ways (American Psychological Association, n.d.). A Pew Research Center study has shown that for teenage boys and girls, daily experiences, pressures, and future aspirations are different (Horowitz, Graf, \& Most, 2019), which could be some of the contributing factors for increased stress in female high school students. Furthermore, a study performed by UNICEF Australia showed that high school girls are more likely than boys to experience stress and anxiety and feel the loss of social connection during the COVID-19 pandemic (Fitzsimmons, 2020).

Our findings suggesting increased pandemic-related stress for senior high school students are not surprising and are acknowledged in the literature (Giannopoulou, Efstathiou, Triantafyllou et al., 2021). Even under normal conditions, senior high school students are faced with unique stressful challenges related to their graduation, college application and preparing for leaving their families and transitioning to college. The COVID-19 pandemic restrictions have amplified these worries and have added uncertainties with regards to their college admission process as well as whether they will be able to attend college in person. Current seniors are also faced with reduced socialization at a very important point of high school life and remain uncertain about milestone experiences such as the senior prom and commencement ceremonies.

Understanding the unique stressors for each high school student should sti- 
mulate innovative and comprehensive solutions by high school educators to better support their students during the COVID-19 pandemic.

Importantly, we found that high school students participating in our study established new perspectives suggestive of PTG. These positive changes should never serve as a reason for advocating suffering for personal growth, but rather for understanding that suffering and grief can co-exist with transformation and growth.

PTG has been shown to be significantly facilitated when people feel being supported and understood (Romeo, Di Tella, Ghiggia et al., 2019; Long \& Wen, 2020). As such, parents and high school educators should provide increased support for students during the pandemic and create a culture of safety and optimism.

The present study has some limitations. First, the small sample size could limit the ability to generalize our findings. Second, our survey is a single-institution study of PTG in students enrolled at Newton North High School-a high school in Massachusetts which may not be representative of other high schools throughout the United States. Surveying a larger group of high school students from multiple institutions with various social, economic, racial, and geographical characteristics would be an important next step in generalizing and validating the findings of our study. Third, the response rate for our survey was low (33.4\%). However, this response rate is commonly found in survey studies involving college or high school students. Fourth, with a response rate of $33.4 \%$ we cannot exclude meaningful differences between students who answered our questionnaire and the non-respondents.

Even with these limitations, we believe our findings provide meaningful insights into the stressful challenges faced by high school students during the COVID-19 pandemic.

\section{Conclusion}

While high school students experience significant stress during the COVID-19 pandemic, our study suggests that they can also experience positive life changes as a result of such a traumatic event. Teachers, counselors, and parents should work together to both support high school students facing adversity and foster resiliency through discussion and exploration of new life perspectives arising from the pandemic. Because high school female students experience more stress during the COVID-19 pandemic, gender-specific interventions are needed to better support them during stressful situations.

\section{Conflicts of Interest}

The author declares no conflicts of interest regarding the publication of this paper.

\section{References}

American Psychological Association (n.d.). Gender and Stress. 
https://www.apa.org/news/press/releases/stress/2010/gender-stress\#: :text=Though\%2 0they\%20report $\% 20$ similar\%20average,and $\% 20$ emotional\%20symptoms $\% 20$ of $\% 20$ stre $\underline{\text { SS }}$

Cabarkapa, S., Nadjidai, S. E., Murgier, J., \& Ng, C. H. (2020). The Psychological Impact of COVID-19 and Other Viral Epidemics on Frontline Healthcare Workers and Ways to Address It: A Rapid Systematic Review. Brain, Behavior, \& Immunity-Health, 8, Article ID: 100144. https://doi.org/10.1016/j.bbih.2020.100144

CDC (n.d.). Anxiety and Depression: Household Pulse Survey. https://www.cdc.gov/nchs/covid19/pulse/mental-health.htm

Fitzsimmons, C. (2020). Teenage Girls More Stressed and Anxious under Lockdown than Boys. The Sydney Morning Herald. https://www.smh.com.au/lifestyle/life-and-relationships/teenage-girls-more-stressed-a nd-anxious-under-lockdown-than-boys-20200515-p54tg8.html

Giannopoulou, I., Efstathiou, V., Triantafyllou, G. et al. (2021). Adding Stress to the Stressed: Senior High School Students' Mental Health amidst the COVID-19 Nationwide Lockdown in Greece. Psychiatry Research, 295, Article ID: 113560. https://doi.org/10.1016/j.psychres.2020.113560

Horowitz, J. M., Graf, N., \& Most, U. S. (2019). Teens See Anxiety and Depression as a Major Problem among Their Peers. https://www.pewresearch.org/social-trends/2019/02/20/most-u-s-teens-see-anxiety-an d-depression-as-a-major-problem-among-their-peers

Kutza, D., \& Cornell, K. (2021). Fostering Post-Traumatic Growth in College Classrooms during COVID-19. Journal of Teaching and Learning with Technology, 10, 12-22.

Long, Y. J., \& Wen, H. (2020). Effects of Different Treatment Methods on Perceived Social Support Ability and Psychological Resilience Level on Post-Traumatic Growth of Colorectal Cancer Patients. Chinese General Practice Nursing, 18, 2031-2033.

Romeo, A., Di Tella, M., Ghiggia, A. et al. (2019). The Traumatic Experience of Breast Cancer: Which Factors Can Relate to the Post-Traumatic Outcomes? Frontiers in Psychology, 10, 891. https://doi.org/10.3389/fpsyg.2019.00891

Salari, N., Hosseinian-Far, A., Jalali, R. et al. (2020). Prevalence of Stress, Anxiety, Depression among the General Population during the COVID-19 Pandemic: A Systematic Review and Meta-Analysis. Global Health, 16, 57. https://doi.org/10.1186/s12992-020-00589-w

Shanafelt, T., Ripp, J., \& Trockel, M. (2020). Understanding and Addressing Sources of Anxiety among Health Care Professionals during the COVID-19 Pandemic. JAMA, 323, 2133-2134. https://doi.org/10.1001/jama.2020.5893

Tedeschi, R. G., \& Calhoun, L. G. (1996). The Posttraumatic Growth Inventory: Measuring the Positive Legacy of Trauma. Journal of Traumatic Stress, 9, 455-471. https://doi.org/10.1002/jts.2490090305

Tedeschi, R. G., \& Calhoun, L. G. (2004). Target Article: "Posttraumatic Growth: Conceptual Foundations and Empirical Evidence". Psychological Inquiry, 15, 1-18. https://doi.org/10.1207/s15327965pli1501 01

Yu, Y., Yu, Y., \& Hu, J. (2021). COVID-19 among Chinese High School Graduates: Psychological Distress, Growth, Meaning in Life and Resilience. Journal of Health Psychology. https://doi.org/10.1177/1359105321990819

Zeng, W., Zeng, Y., Xu, Y. et al. (2021). The Influence of Post-Traumatic Growth on College Students' Creativity during the COVID-19 Pandemic: The Mediating Role of General Self-Efficacy and the Moderating Role of Deliberate Rumination. Frontiers in Psychology, 12, 1264. https://doi.org/10.3389/fpsyg.2021.684354 


\section{Supplement}

\section{Survey questions}

1) What is your gender?
a) Femal
b) Male
c) Prefer to describe myself
d) Prefer not to say

2. What grade are you currently in?
a) $9^{\text {th }}$ grade
b) $10^{\text {th }}$ grade
c) $11^{\text {th }}$ grade
d) $12^{\text {th }}$ grade

3) What is your ethnicity?
a) White
b) Hispanic
c) African American
d) Native American or American Indian
e) Asian or Pacific Islander
f) Other:
g) Prefer not to say

4) How would you describe the overall level of stress that you have experienced during the COVID-19 pandemic?
a) None
b) Minimal
c) Moderate
d) Severe
e) Prefer not to say

5) On a scale of 1 to 5 ( $1=$ least stressful; $5=$ most stressful), please indicate the stress level that you have experienced during the COVID-19 pandemic related to the following items:
a) Risk of you or your family getting infected with COVID-19
b) Social isolation
c) Quality of education
d) Outlook for the future
e) Family financial situation

f) Other:

6) On a scale of 1 to 5 ( $1=$ strongly disagree; $5=$ strongly agree), please indicate the extent that you agree with the following statements with regards to the changes that you have experienced as a result of the COVID-19 pandemic:
a) I changed my priorities about what is important in life
b) New opportunities are available which wouldn't have been otherwise
c) I feel I can rely on people in times of trouble
d) I have a greater sense of closeness with others
e) I have a greater appreciation for my own life's value
f) I appreciate each day more
g) I have a better understanding of spiritual matters
h) I discovered that I'm stronger than I thought I was
i) I am more willing to express my emotions
j) I developed new interests
k) I am better able to accept the way things work out
l) I have more compassion for others
m) I am more likely to try to change things that I am unsatisfied with 